\title{
Cooperating Teachers' Practices in Handling Pre-service Teachers in Elementary Schools of Davao City
}

\author{
Emmie M. Cabanlit*
}

\begin{abstract}
Cooperating teachers' (CT) capability to handle preservice teachers (PST) is viewed as a critical collaborating role in teacher education program. This study investigated cooperating teachers' practices in handling pre-service teachers, their bases for these practices, and implications for professional enhancement. Qualitative thematic-deductive analysis under the consensual qualitative research (CQR) was used in the study, using semi-structured interview as instrument for drawing out constructs and narratives from the purposive samples. Practices performed by the cooperating teachers, as shown by the results, were categorized as mentoring and supervisory. Practices such as soliciting feedback from daily experiences, providing simple or modest physical resources or accommodation, and demonstrating ways in building collegial skills fall under mentoring practices. Supervisory practices consisted of assessing the readiness of the PSTs to handle classroom responsibilities, checking and approving the lesson plan, conducting class observation, honing the PSTs' skills in holding co-curricular activities, conducting conferences to elicit agreement and feedback, and monitoring progress in teaching. These said practices were anchored on experiential insights, practical applications, colleague consultation, pre-service teachers'
\end{abstract}

* Emmie Cabanlit is faculty of the College of Education of the University of Southeastern Philippines. She can be reached at this email address: emmie.cabanlit@usep.edu.ph. 
manual, and orientations from the sending school. Based on the findings, cooperating teachers are still wanting of competencies from in-service training to augment their personalized practical practices. This study recommends that an enhancement training program be provided to enrich practices in handling future PSTs who are soon graduates of the new teacher education curriculum.

Keywords: cooperating teachers, pre-service teachers, mentoring, supervisory practices

Practicum has been considered as a site where pre-service teachers practice the art of teaching in real school context with them assigned to one teacher and class for specific block of time (Tuli \& File, 2010). This school-based experience allows them to be shaped under the guidance of cooperating teachers who are viewed to have a very critical role in assuming their role in day-to-day experiences in relation to classroom practices like curriculum, evaluation and pedagogy (Lingam, 2002; Ralph, 2007; Tuliand File, 2010).

Practicum experience has been observed by the College of Education of the University of Southeastern Philippines since the start of this academic program. No study however has been conducted to determine whether the program has achieved its intended outcomes or not. Each year, a memorandum of agreement is signed between the College of Education-USEP and the cooperating agency for the pre-service teachers to undergo regular practicum. The cooperating teachers who handle these pre-service teachers are chosen by subject area coordinators with the approval of the school principals. The PSTs have to satisfy the required number of practicum hours specified in the curriculum.

When pre-service teachers are turned over to their cooperating teachers, mentorship then begins. Mentors' performance of their roles and how they carry about their performance are not well documented in 
current research (Cherian, 2007). On the other hand, Rowe, Mackaway, $\&$ Winchester-Seeto (2012) pointed out that those who are asked to mentor the cooperating teachers often have a different understanding of how to perform their role to meet the expectation of pre-service teachers as well as the sending college.

Basically, cooperating teachers perform different practices in assuming their roles in helping, shaping and preparing pre-service teachers in the real context of teaching. They act as mentors who guide pre-service teachers by building trust and modeling positive behaviors. An effective mentor knows that his role is to be authentically engaged in his work and being regulated to tune into the needs of the mentee. A supervisor on the other hand takes charge of monitoring the less experienced person in matters related to his job. He is concerned with the performance of the task (Alila, Uusiautti, \& Määttä, 2016; Ralph and Walker, 2010).

In like manner, every cooperating teacher is expected to do varied roles. Supervising is task-oriented while mentoring is about caring for the mentee for long-term development (Acker, 2011). The study of Van Ginkel, et al. (2016) on Adapting mentoring to individual differences in novice teacher learning: the mentor's viewpoint identified four mentoring activities done by mentors, namely: 1) aligning mutual expectations, 2) attuning to the novices' emotional state, 3) adapting the mentoring conversation to match the reflective capacity of the novice teacher, and 4) building tasks from simple to complex relative to the novice competence level.

Aligned to performing these roles, Neville, Sherman, and Cohen (2005) stressed that the amount of quality time the supervisor spends to mentor a cooperating teacher has a significant contribution to the rich experiences acquired (Ralph, 2007; Ralph, Walker, and Wimmer, 2008). 
Lingam (2002), Ralph (2007), Tuli \& File (2010) have shown in their studies that PSTs are satisfied in applying their academic theory into real teaching; they're satisfied as well with their inter-personal and professional relationships during the clinical experience, and with their personal growth related to competencies and the confidence they have built.

There were however studies which revealed pre-service teachers' disappointments on cooperating teachers' lack of proper and constructive feedback, so as the lack of teaching and learning resources (Allen \& Turner, 2012; Gaffey, n.d.). There were likewise negative impacts of the practicum experiences especially in the areas of supervision found by Lingam (2002), Mohan, Lingam, and Chand (2017), and Ralph (2007).

Mentioned above are substantial points to consider in the teacher education program because they have consequences to the performance of pre-service teachers. Along the shaping and preparation for real world teaching, when pre-service teachers are exposed to handle so-called real world teaching during their practicum experience, cooperating teachers perform major critical roles. CTs are expected to be professionals in their dealing with pre-service teachers, i.e. on matters related to mentoring, coaching, and giving feedback. Absence of feedback, such as in the forms of adequate advice and guidance, from cooperating teachers could lead PSTs to a state of uncertainty and hamper their personal development during practicum experience (Lingam, Lingam, and Raghuwaiya, 2014).

Results from these past studies are alarming and therefore need to be highlighted in the improvement of the College of Education's practicum program. Determining cooperating teachers' varied ways in handling college pre-service teachers would generate useful inputs that could benefit both the pre-service teachers and the cooperating teachers. When cooperating teachers are professionally skilled to handle pre-service teachers, there is probable beneficial impact to the graduates 
of the program. Conversely, if cooperating teachers are still wanting of professional advancement, then findings of the study can identify what could be done to improve professional practices.

In this study, cooperating teachers' practices in handling pre-service teachers in elementary education are investigated using qualitative tools. Specifically, it determined the cooperating teachers' practices in handling pre-service teachers, how they demonstrated these practices, the bases for demonstrating these practices, and their implications.

One of the significant factors to prepare the pre-service teachers into the field is to bring them to the actual world of teaching in the presence of a cooperating teacher. This serves as a learning laboratory for preservice teachers where they can expect to learn from their CTs both practical and technical skills in the context of generalist, early childhood, or SPED pre-service education.

This study is anchored on Calderhead and Shorrock's theory of teacher education, particularly in regard to the learning experience of pre-service teachers with cooperating teachers. The theory stipulates five types of learning experiences that cooperating teachers impart to pre-service teachers: knowledge accumulation, where all information vital to the task are given by the cooperating teachers; performance learning, where cooperating teachers show the task of doing the job as teacher in the classroom; practical problem-solving, where planning and thinking solve and meet daily constraints and opportunities that confront classroom routines; learned relationship, where establishing a mentormentee relationship should be initiated by a cooperating teacher; and processes of assimilation in learning to teach, where cooperating teachers guide the pre-service teachers in discriminating one strategy, approach or skill from the other, and learning more to be able to teach effectively. 


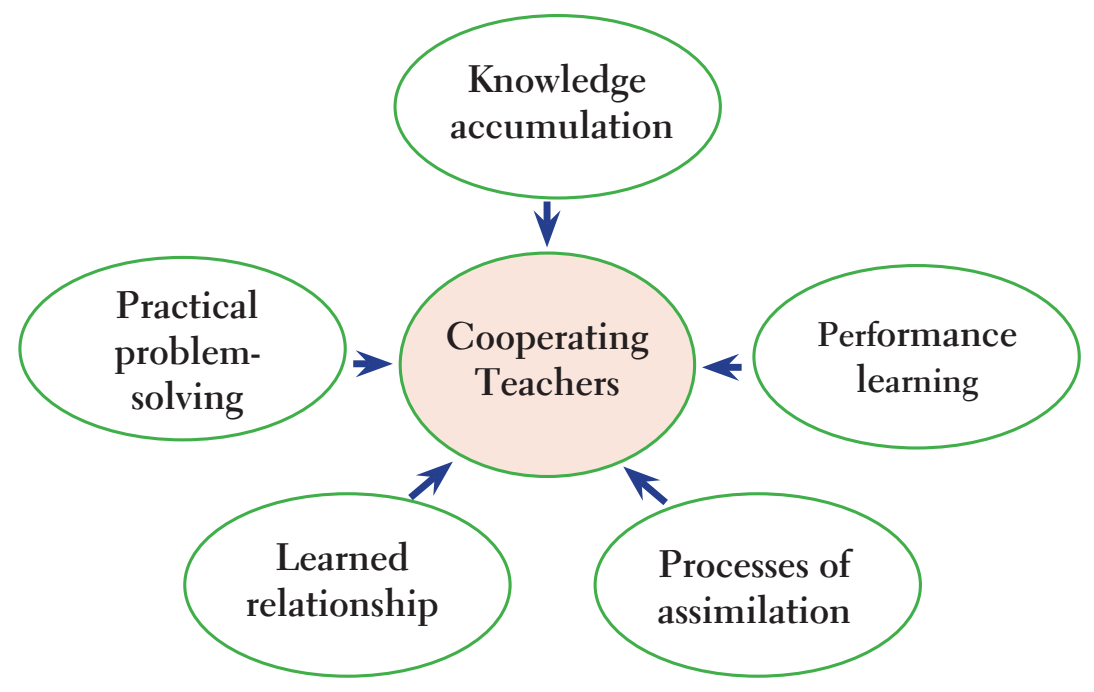

Figure 1. Calderhead and Shorrock's theory of teacher education.

\section{The study's qualitative tool}

Using qualitative inquiry in finding out cooperating teachers' practices in handling pre-service teachers, the study employed consensual qualitative research $(\mathrm{CQR})$, a practical design in investigating social phenomena; in the case of the study, it adopted the use of open-ended questions to ask cooperating teachers' experiences. Primary data were taken from the interviews as well as researcher's observations during the conduct of practice teaching. Answers provided by the CTs about their practices were validated by holding information conversations with the PSTs during class observations. These three steps in using CQR were particularly followed, namely: developing and coding domains; constructing core ideas; and developing categories to describe the consistencies across analysis. Thematic-deductive analysis was used to go through the processes of figuring out meanings derived from the textual 
matter (or interview data), given the contexts involved. Applicability of results and their implications were likewise derived and discussed in this paper.

Cooperating teachers who were handling pre-service teachers in the elementary whether generalists, early childhood, or SPED were purposively selected as participants of the study. They must have served at least two years in handling pre-service teachers in the public school. Teachers who have experienced two years as cooperating teachers are not considered neophyte in the job and are assumed to have gained some skills in mentoring and supervisory work.

Some procedural steps were observed in gathering the data. To preserve the confidentiality of the information, identities of schools and participants, as well as the identity of pre-service teachers under their care, are not mentioned here.

\section{Cooperating Teachers and their Major Practices: Results of the Study}

Qualitative thematic analysis results showed that there were two (2) major categories of practices of cooperating teachers towards pre-service teachers during the span of practicum experience. These are mentoring activities and supervisory practices. Mentoring activities were geared towards building personal relationship and assistance, while supervisory practices were directed towards professional upliftment and experiential enrichment. 


\section{Mentoring activities of CTs}

CTs performed mentoring activities towards PSTs on a day-to-day basis. This study revealed a number of mentoring activities, as follows.

Soliciting feedback from daily experiences. This is one of the ways a cooperating teacher builds the confidence of pre-service teachers. The CT-research participants shared that asking feedback from their PSTs is a good way to start the mentoring activity and the supervisory practice. Even a simple question as how was your day could establish a communication line between CT and PST, creating a sense of belongingness between them. Constant asking of questions could lead to confidence- and trustbuilding, which later results to a collegial or professional relationship.

CTs likewise believed that PSTs bring with them major feelings of excitement and anxiety - excitement due to new experiences as required by their degree, and anxiety because these experiences will require the application of knowledge, skills and attitude in the presence of a CT in the real classroom setting. CTs understand that lack of feedback from supervisors or cooperating teachers may leave the students in a state of ambivalence and could hinder their development during the practicum experience (Lingam, Lingam, and Raghuwaiya, 2014).

Providing simple or modest physical resources/accommodations. Practice teachers were provided simple or modest resources or accommodations by the CTs such as table and chairs where the PSTs could prepare their lesson plans and other related work. CTs likewise provided PSTs supplies for making visual instructional materials: writing sheets, cartolina, manila paper, marking pens, crayons, etc. However, most of the time, PSTs bought their own materials due to scarcity of school supplies. 
Demonstrating ways in building collegial skills. The CTs saw the need to mentor the PSTs in building collegial relationships. The CT himself/herself has personal ways that could serve as model behavior for the PSTs to follow. One CT shared "I allow (the PST) to observe how I approached our Grade Head and other colleagues when dealing with some queries about work." Other CTs said they oriented the PSTs on how to approach some personalities in the school with respect and courtesy. These relationships reveal how cooperating teachers help PSTs to start their new role as novice teacher (van Ginkel, Oolbekkink, Meijer, \& Verloop, 2016).

\section{Supervisory practices of CTs}

Assessing the readiness of the PSTs to handle classroom responsibilities. To assess the readiness of the PST, the CT asks for the former's lesson plan, checking its sequential elements. Most of the assessment concerns of the CTs were geared towards lesson planning and a little of classroom management. Lesson planning is the central concern, since it is "the basic thing for a teacher, while classroom management will just be learned by PSTs as they stay in the classroom," one CT revealed.

Checking and approving the lesson plan and teaching strategies. These mentoring activities are basic preparations before the PSTs' deployment in the field. CTs check if lesson plan objectives are based on the curriculum guide of a certain grade and subject, and if activities prepared were planned towards attainment of objectives. However, religiously checking all lesson plans before allowing the PSTs to teach may not always be necessary as, according to some of the CTstudy participants, there are PSTs that "can already be trusted" in the preparation of lessons plans. 
With good mentoring relationship, instructional strategies can be enhanced. CTs are expected to demonstrate to the PST how teaching is delivered in a given grade, subject, to certain types of students, and classroom context. PSTs observe their ways of teaching, emulating the proper strategies. CTs shared that "familiarization of ways to handle a certain grade level may vary from (PSTs') previous experiences during the field study." After the observation, PSTs share with their CTs what they have observed, even including "students who do not pay attention in class." CTs realize that PSTs observe not only the teaching strategies but also the behavioral make-up of the children. The researcher asked a PST to validate this finding, with the research participant affirming that PSTs observe the students too "so that we will know (which) students could help us when it is our turn to teach."

Conducting class observation. One of the major supervisory practices engaged in by a CT is to conduct class observation. During these class observations, CTs find out if the PST was able to "deliver the lesson to the students", if they "achieved the objectives", and if "activities were effective in attaining the objectives of the lesson." When asked about classroom management, the CTs said that adjustment of PSTs in handling the pupils is learned as they immerse on a daily basis with their CTs.

Honing PST skills in conducting co-curricular activities. Cooperating teachers believe in the capability of PSTs in building activities to enforce the learning of the curriculum. With this, they assigned PSTs to handle and facilitate classroom and school events like monthly observance and celebrations, foundation day, closing exercises and other related cocurricular activities. 
Conducting conferences to elicit agreement and feedback. Cooperating teachers had informal conferences with the PSTs during the pre- and post-observation of classes. For pre-observation, the CTs and PSTs agreed on the learning area to be observed, the topic, time or schedule, and section and grade (for those handling across sections and across learning areas). Post-observation involved giving of feedback and evaluation. Asked regarding experiencing any difficulty in handling class observations and conferences with PSTs, one CT-research participant said she found it difficult to handle a thorough clinical observation since she is not that conversant with "deeper" processes involved in clinical observation. When asked what her basis was for her practice, she shared that she followed what she had experienced from her principal who conducts its own observations in her class.

Monitoring progress in teaching. CTs monitor their PSTs' progress in teaching through the rubrics attached to the PST's manual. Aside from the rubrics, CTs also consider what they regularly see in PSTs' behavior in the classroom and how they handle classroom responsibilities part of the rating performance.

\section{Bases for Cooperating Teachers' Practices}

Any teacher could become a cooperating teacher of a pre-service teacher provided he or she is recommended by the immediate superior to handle the responsibility. Whether he/she acquired training or not, or even without experiences in handling PSTs, as long as the CT is capable of performing the tasks related to the job or assignment, then he/she could become a cooperating teacher. 
The following are the CTs' bases for their practices, as revealed by the research:

Experiential insights. Mentoring and supervisory practices of CTs are based on experiential insights. Operationally, experiential insight refers to the soft skills learned by the cooperating teachers from their superiors and as they grow in their profession. This type of skills can easily connect the mentor and the mentee in meaningful and engaging ways. At times, cooperating teachers are underprepared, hence they tend to be guided by their own personal experiences of being coached (as coaching practices are themselves synonymous to teaching practices).

Practical applications. The CTs said that what they shared to their practicum students are those which they deem useful and practical to the handling of immediate problems and situations that arise in teaching and learning conditions. Practical applications are resorted because as the CTs shared, "we do not have enough training to handle practice teachers."

Collegial consultation. Another basis or resource of cooperating teachers in their mentoring and supervisory responsibilities is colleague consultation, especially ones whom they have seen had enough experiences in doing the job. According to one CT, "When I am confused on what to advise to the PST, especially when I notice a somewhat weak personality, I ask advice from my colleagues." Another said, "it is helpful to consult my co-teachers especially those who are accustomed to handling practice teachers since they have gained experiential insights from previous involvement." 
Pre-service teachers' manual. Cooperating teachers said they found the pre-service manual given by the University a good and quick guide for their actions, as one CT-research participant confirmed: "At times when I need to be sure if I already performed all my responsibilities toward my practicumer, I scan the PST manual which specifies what should be done from my end." When asked if the PST manual is already enough to have a sure guide in handling PSTs, participants said they still need in-depth training especially on instructional supervisory practices. They also expressed the need to enhance further their skills especially since they will be handling a new breed of pre-service teachers who are products of the K-12 curriculum.

Orientation from the sending school. It is the primary duty of the sending schools, colleges and universities to give a brief orientation to the school heads and teachers of the cooperating schools. During orientation, both the receiving school and the sending school lay down foundational policies and major responsibilities. The sending school shares the purpose, responsibility and accountability of the cooperating principal and teachers towards the conduct of the pre-service teaching experiential learning, while the receiving school orients the PSTs on the school policies and other essential matters to be observed with respect to their stay in the cooperating school. 
The cooperative teachers' practices in handling pre-service teachers can be summarized in the framework below.

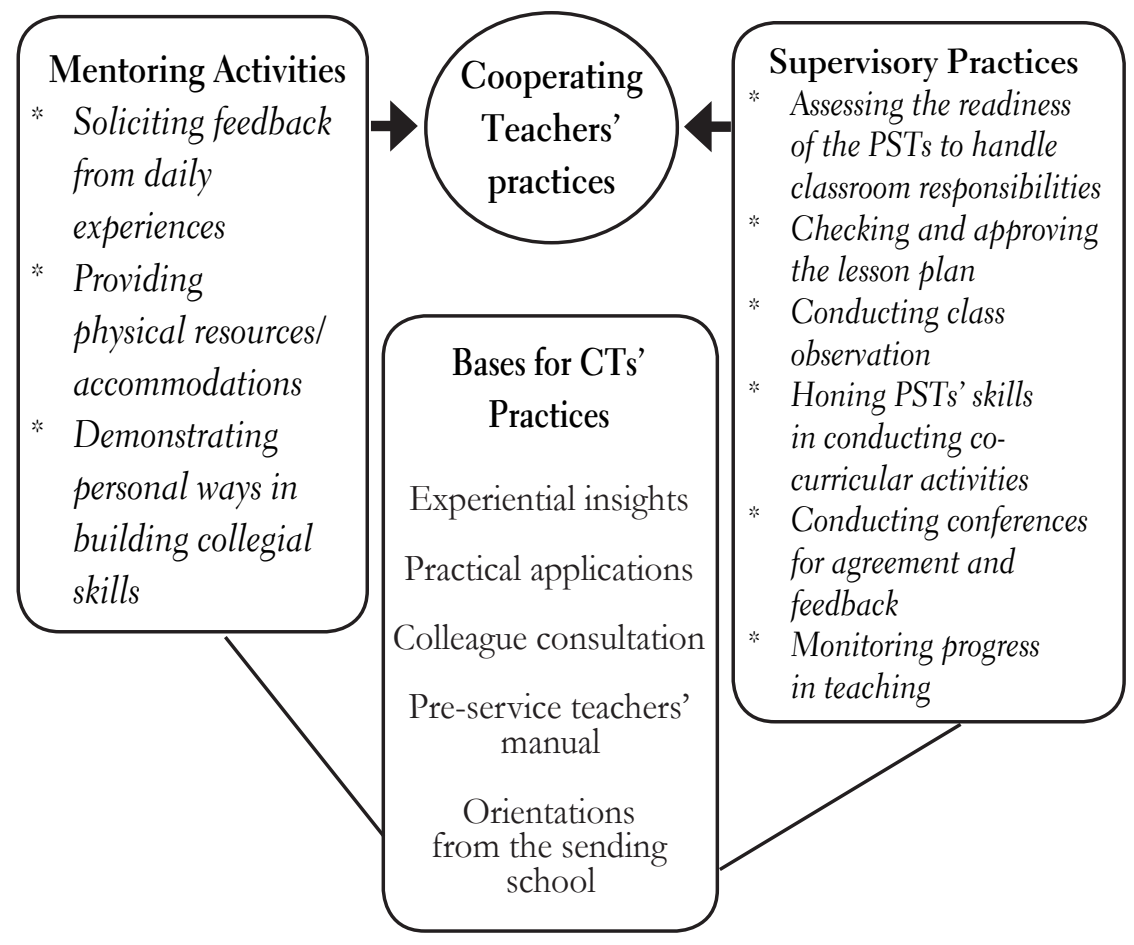

Fig. 2. Cooperating Teachers' Practices in Handling Pre-service Teachers in Elementary Schools of Davao City

\section{Discussion and Implications}

Based on the qualitative findings of the study, the practices of the CTs were hinged on practical knowledge and skills generated from routinely personal and collegial experiences and not from in-service or formal training especially with respect to the clinical supervision 
approach. Hence, it can be said that CTs fall short of the practices. As such, they should be provided with clinical supervision trainings to enhance their supervisory and mentoring practices, especially since they now accept a new breed of pre-service teachers who are graduates of the K-12 curriculum. These training could be according to the following levels: clinical, peer coaching, cognitive coaching, mentoring, and reflective coaching. Such training needs can be addressed by both the sending and receiving schools of pre-service teachers.

A proposed enhancement training program can be patterned after the University of Texas at Austin's CS-CARE Program. This is Clinical Supervision with critical content $(\mathbf{C})$, appreciation $(\mathbf{A})$, reflection $(\mathbf{R})$, and is experiential $(\mathbf{E})$. The CS-CARE Program is meant to re-envision and re-engineer what it means to be a cooperating teacher in the $21^{\text {st }}$ century in which it will deliver critical content of the engagement, guided by appreciative instructional supervision, in real context of experience, which eventually leads to reflective practice of a teacher. The program can be conducted through a series of sessions and could be a continuing engagement between the cooperating school and the university.

Fig. 3. The Schematic Model of CS-CARE Program

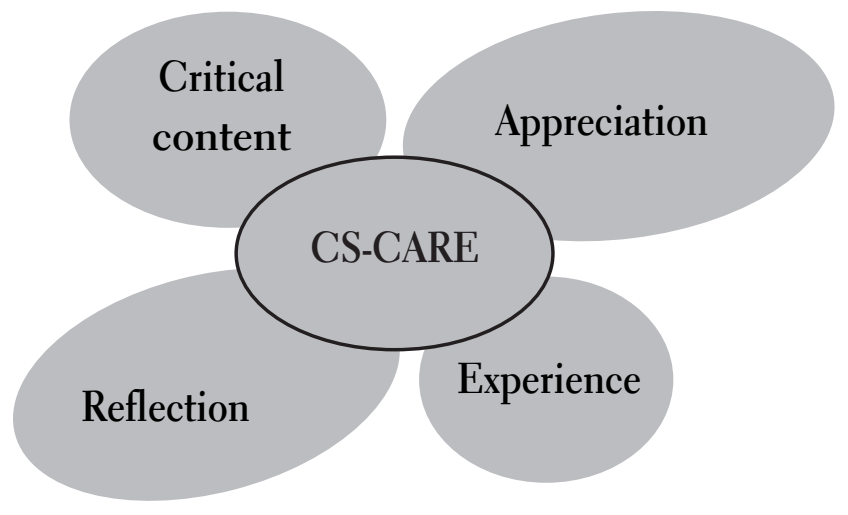


The target participants of the program are teachers who will be handling PSTs from kindergarten to senior high school levels. As mentors and coaches of the 'new breed' of PSTs, they are expected to enhance their skills in the four dimensions of the CS-CARE model so as to catch up with the kind of learners in the 'millennial age of education'. Skills in critical thinking, communication, collaboration, and creativity as well as the achievement of greater self-efficacy in mentoring pre-service teachers are expected to be elicited from the program.

Findings from the study have shown that the practices of cooperating teachers in handling their PSTs were based on gained insights and practicality through experience over time more than on skills derived from formal training. This implies that there might have been less than adequate in-service trainings provided by the Department of Education to CTs. This inadequacy needs to be addressed to make PSTs more effective in handling and mentoring especially the incoming new breed of practice teachers who are products of the new BEEd program from the K-12 curriculum. Attendance to such specialized trainings could hopefully arrest the apprehensions of the cooperating teachers in handling pre-service teachers. 


\section{References}

Alila, S., Uusiautti, S., and Määttä, K. (2016). The Principles and Practices of Supervision That Supports the Development of Inclusive Teacherhood. Journal of Education and Learning, 5(3), 297. https://doi. org/10.5539/jel.v5n3p297

Allen, J. M., and Turner, D. (2012). School Practitioners' and University Staff Members' Perceptions of the Pre-Service Teacher Education Practicum: a Comparative Study, 10.

Cherian, F. (2007). Learning to Teach: Teacher Candidates Reflect on the Relational, Conceptual, and Contextual Influences of Responsive Mentorship. Canadian Journal of Education / Revue Canadienne de l'éducation, 30(1), 25. https://doi.org/10.2307/20466624

Gaffey, C. (n.d.). Facilitating Practicum Supervision: Participants' perceptions, 30 .

Lingam, G. I. (2002). Practicum component: Preparation of teachers for the real world of work, 24, 15.

Lingam, G., Lingam, N., and Raghuwaiya, K. (2014). Effectiveness of School Strategic Planning: The Case of Fijian Schools, 8(7), 7.

Mohan, P. P., Lingam, G. I., and Chand, D. D. (2017). An investigation of teachers' professional development practices in a rural Fijian secondary school. Waikato Journal of Education, 22(4). https://doi. org/10.15663/wje.v22i4.540

Ralph, D. E. (2007). The Practicum in Professional Education: Pre-Service Students' Experiences, 1(2), 17.

Ralph, Edwin G., and Walker, K. (2010). Enhancing Mentors' Effectiveness: The promise of the Adaptive Mentorship model. McGill Journal of Education, 45(2), 205. https://doi.org/10.7202/045604ar 
Ralph, E.G., Walker, K., and Wimmer, R. (2008). The Clinical/Practicum Experience in Professional Preparation: Preliminary findings. McGill Journal of Education, 43(2), 157. https://doi.org/10.7202/019580ar

Rowe, A., Mackaway, J., and Winchester-Seeto, T. (2012). 'But I thought you were doing that' - Clarifying the role of the host supervisor in experience-based learning., 22.

Tuli, F., and File, G. (2010). Practicum Experience In Teacher Education. Ethiopian Journal of Education and Sciences, 5(1). https://doi. org/10.4314/ ejesc.v5i1.56316

Van Ginkel, G., Oolbekkink, H., Meijer, P. C., and Verloop, N. (2016). Adapting mentoring to individual differences in novice teacher learning: the mentor's viewpoint. Teachers and Teaching, 22(2), 198-218. https://doi.org/10.1080/13540602.2015.1055438 